\title{
Analysis of large oxygenated and nitrated polycyclic aromatic hydrocarbons formed under simulated diesel engine exhaust conditions (by compound fingerprints with SPE/LC-API-MS)
}

\author{
Christoph Adelhelm • Reinhard Niessner • \\ Ulrich Pöschl • Thomas Letzel
}

Received: 14 March 2008 /Revised: 30 April 2008 / Accepted: 5 May 2008 / Published online: 16 June 2008

(C) The Author(s) 2008

\begin{abstract}
The analysis of organic compounds in combustion exhaust particles and the chemical transformation of soot by nitrogen oxides are key aspects of assessment and mitigation of the climate and health effects of aerosol emissions from fossil fuel combustion and biomass burning. In this study we present experimental and analytical techniques for efficient investigation of oxygenated and nitrated derivatives of large polycyclic aromatic hydrocarbons (PAHs), which can be regarded as well-defined soot model substances. For coronene and hexabenzocoronene exposed to nitrogen dioxide under simulated diesel exhaust conditions, several reaction products with high molecular mass could be characterized by liquid chromatographyatmospheric pressure chemical (and photo) ionization-mass
\end{abstract}

C. Adelhelm · R. Niessner · U. Pöschl

Institute for Hydrochemistry, Technische Universität München,

Marchioninistr. 17,

81377 Munich, Germany

T. Letzel $(\bowtie)$

Analytical Research Group, Chair of Biopolymer Chemistry,

Technische Universität München,

Weihenstephaner Berg 3,

85354 Freising, Germany

e-mail: t.letzel@1rz.tu-muenchen.de

Present address:

C. Adelhelm

Max-Planck-Institut für Plasmaphysik,

Boltzmannstr. 2,

85748 Garching, Germany

Present address:

U. Pöschl

Max-Planck-Institut für Chemie,

Joh.-Joachim-Becher-Weg 27,

55128 Mainz, Germany spectrometry (LC-APCI-MS and LC-APPI-MS). The main products of coronene contained odd numbers of nitrogen atoms $(\mathrm{m} / \mathrm{z} 282,256,338)$, whereas one of the main products of hexabenzocoronene exhibited an even number of nitrogen atoms $(\mathrm{m} / \mathrm{z}$ 391). Various reaction products containing carbonyl and nitro groups could be tentatively identified by combining chromatographic and mass spectrometric information, and changes of their relative abundance were observed to depend on the reaction conditions. This analytical strategy should highlight a relatively young technique for the characterization of various soot-contained, semi-volatile, and semi-polar reaction products of large PAHs.

Keywords LC-API-MS · High-performance liquid chromatography · Mass spectrometry - Oxidation · Nitration . PAH

\section{Introduction}

Soot particles are hazardous environmental pollutants that account for a major fraction of fine air particulate matter in urban areas. They can cause and enhance respiratory, cardiovascular, and allergic diseases, and they influence atmospheric chemistry, physics, and climate [1-3].

In compliance with present and future emission limits of diesel particulate matter (DPM), a wide range of particle trapping and exhaust treatment technologies have been introduced or are under development, e.g. ceramic diesel particulate filters (DPF) or novel particle traps and oxidation catalysts with open deposition structures [4-8]. These technologies generally require a regeneration method which efficiently oxidises and gasifies soot deposited in the filter or catalyst structures. Usually the regeneration is 
either based on discontinuous oxidation by $\mathrm{O}_{2}$ at temperatures higher than $700 \mathrm{~K}$ (regular heating intervals) or continuous oxidation at temperatures in the range of 500$700 \mathrm{~K}$ with $\mathrm{NO}_{2}$ as the main oxidant. Thus, the reaction between soot and $\mathrm{NO}_{2}$ is of high importance, because prevention of toxic or mutagenic reaction components is essential.

Chemical investigations of the oxidation process of carbon and soot using ozone or nitrogen dioxide have often been performed by spectroscopy (IR, DRIFTS) in order to detect oxygen-containing groups on the soot surface after oxidation [9-12], or to detect gaseous components formed during the reaction, e.g. HONO [13] or $\mathrm{CO}_{2}[14,15]$ to evaluate the oxidation kinetics. Recently, the influence of the soot microstructure has been studied in detail $[16,17]$.

Soot consists mostly of carbon and is composed of agglomerated primary particles with diameters of $10-30 \mathrm{~nm}$ that comprise nanocrystalline $[8,17-20]$ and amorphous domains. The amorphous domains are disordered mixtures of polycyclic aromatic hydrocarbons (PAH) and other organic and inorganic components $[8,18,21,22]$. As a simplified view, these amorphous domains can be regarded as giant PAHs (e.g. coronene, $\mathrm{C}_{24} \mathrm{H}_{12}$ in Fig. 1a, and hexabenzocoronene (HBC), $\mathrm{C}_{42} \mathrm{H}_{18}$, in Fig. 1b), although the amorphous parts of soot are not expected to have the same planar structure as HBC. However, a recent publication showed that HBC is a good model for the amorphous part of diesel soot [8]. Therefore, with the oxidation of $\mathrm{HBC}$ by $\mathrm{NO}_{2}$ one is able to mimic the oxidation of diesel soot with a molecularly defined substance. This allows examination of the oxidation products with a well-established chemical analysis method.

Liquid chromatography-mass spectrometry (LC-MS) coupled with atmospheric pressure ionisation (API) is known to be a strong tool for analysis of several classes of organic pollutant $[23,24]$. The API sources "atmospheric

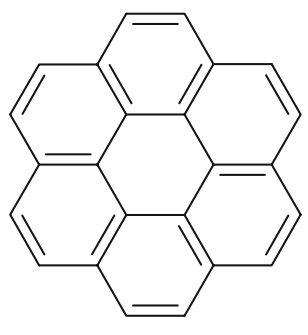

(a)

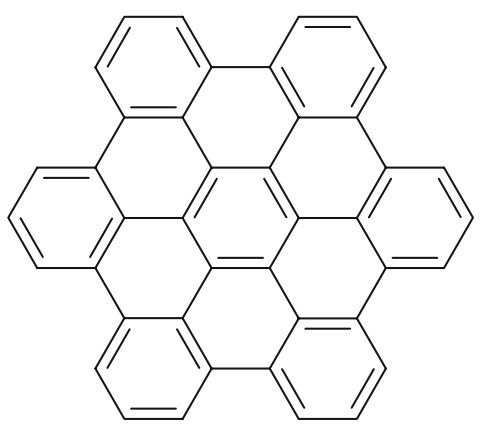

(b)
Fig. 1 Structural formulae of PAHs oxidised in this study: (a) coronene $\left(\mathrm{C}_{24} \mathrm{H}_{12}\right)$, (b) hexabenzocoronene, $\mathrm{HBC}\left(\mathrm{C}_{42} \mathrm{H}_{18}\right)$ pressure photoionization" (APPI) and "atmospheric pressure chemical ionization" (APCI) are very well suited to the ionisation of small uncharged aromatic molecules separated by LC [25]. LC-APCI-MS, for instance, was successfully used to determine high-molecular-mass polycyclic aromatic hydrocarbons from environmental samples [26]. Letzel et al. described the suitability of APCI-MS for analysis of semi-polar oxidation products (phenols, quinones) from the heterogeneous reaction of benzo $[a]$ pyrene, water, and ozone [27, 28]. Later, an effective LC-APCI-MS method was published for the characterization of nitrated PAHs on aerosols [29].

However, to our present knowledge there have been no LC-API-MS investigations to research the oxidation of large, symmetric, and stable PAHs with $\mathrm{NO}_{2}$ at elevated temperatures.

In this work we present a simple approach to oxidize the large PAHs coronene and hexabenzocoronene with $\mathrm{NO}_{2}$ and $\mathrm{O}_{2}$ at high temperatures. The aim of this study was to vary strongly the oxidation conditions (temperature, $\mathrm{NO}_{2}$, and $\mathrm{O}_{2}$ content) and to study the effect of this on the oxidised species detected in subsequent analysis. An established pre-separation step using solid-phase extraction $[27,28]$ was adapted with fast LC-MS for fingerprint analysis of partially oxidized PAHs. This study helps to close the gap between theoretical calculations [30] and the limited amount of experimental data present in the literature today.

\section{Experimental}

Sample preparation

Coronene (0.5 mg; 99.8\%; PAH Institute, Dr Schmidt, Greifenberg, Germany) was spread on a quartz-fibre filter (4.5 cm, QF-10, Macherey Nagel, Düren, Germany) by dropping a cyclohexane solution on the filter and evaporating the solvent.

HBC was obtained from the research group of Professor Müllen, Max-Planck Institute for Polymer Research, Mainz, Germany. Ultrafine HBC particles $(1.0 \mathrm{mg})$, produced by sublimation under a stream of nitrogen [31], were collected on a quartz-fibre filter.

\section{Oxidation procedure}

An appropriate quartz-glass apparatus was manufactured to oxidise the PAHs at elevated temperatures and stop the reaction immediately by cooling from outside with liquid nitrogen (Fig. 2). The reaction gases (nitrogen 5.0 (i.e. $99.999 \%$ purity), oxygen 3.5 (i.e. $\geq 99.95 \%$ purity), and nitrogen dioxide (1010 ppm $\mathrm{NO}_{2}$ in nitrogen 5.0)) were 
Fig. 2 Schematic representation of the setup used for oxidation of large PAH. Qt: Quartz tube filled with quartz beads, externally heated by Ht. $H t$ : Quartz tube wrapped by heating coil. $U t$ : U-like reaction tube, isolated with glass wool. Ft: Filter with large PAH. Hc: Heating control unit. $\mathrm{Rm}$ : Rotameter. $\mathrm{Hu}$ : Humidifier

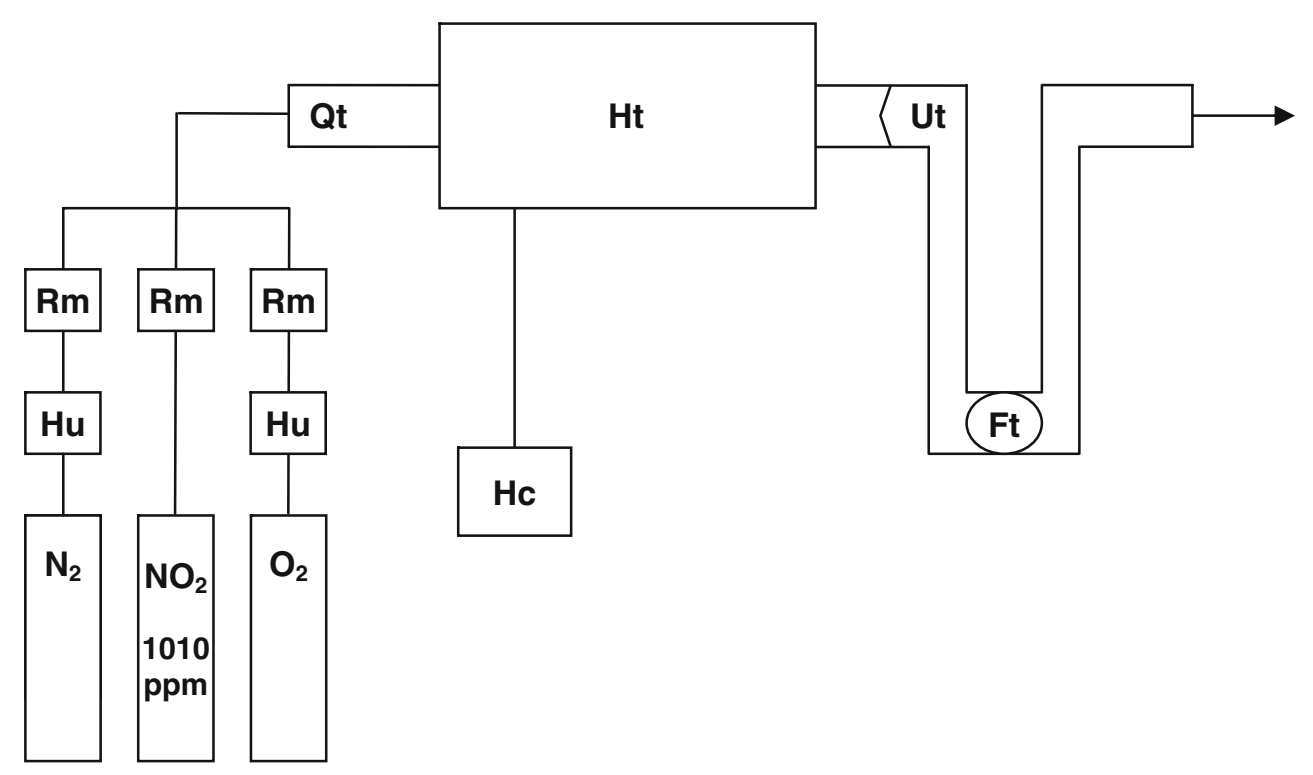

supplied in gas bottles (Messer Griesheim, Krefeld, Germany) and the gas flows were controlled by rotameters (Rota Yokogawa, Ratingen, Germany). Nitrogen and oxygen were moistened by streaming through a water-filled washing bottle using a glass frit. By varying the three gas flows (overall flow $4 \mathrm{~L} \mathrm{~min}^{-1}$ ) two different $\mathrm{NO}_{2}$ concentrations $(250$ and $500 \mathrm{ppm})$ and three different $\mathrm{O}_{2}$ concentrations $(0,50$, and $75 \%)$ could be achieved.

The gas mixture was heated by flowing through the quartz-glass tube, Qt $(60 \mathrm{~cm}, d=1.3 \mathrm{~cm})$, containing quartz beads to optimise heat transfer. Temperature regulation was performed by use of a surrounding heating tube, $H t$, supplied by a control unit, Hc (HT 52, Hillesheim, Germany). In the subsequently connected U-tube, Ut $(10 \mathrm{~cm} \times 3.5 \mathrm{~cm})$, isolated by glass wool, the hot gases reacted with the PAH-loaded filter. The temperature at the position of the filter can easily be regulated by varying the temperature of the heating tube (ht). The temperature at the filter was determined in previous test experiments using a thermocouple and pure nitrogen. All parts were joined by glass flanges or hose connections (Tygon, SaintGobain, Charny, France).

After oxidising the large PAHs ( $2 \mathrm{~h}$ for coronene, $1 \mathrm{~h}$ for HBC samples) the reaction was stopped immediately by changing the gas mixture to pure nitrogen and simultaneously cooling the U-tube with liquid nitrogen, using an appropriate Dewar flask.

\section{Extraction and pre-separation}

The remaining PAH and oxidation products were extracted from the filters, pre-separated (using solid-phase extraction) and concentrated by applying a method developed earlier $[27,28]$. The filters were extracted in $4 \mathrm{~mL}$ of a $1: 1: 1$ mixture of toluene (LiChrosolv, Merck, Darmstadt, Germany), dichloromethane (extra pure, Merck), and methanol (HPLC-gradient grade, Merck) in an ultrasonic bath (Sonorex, Moerfelden, Germany) for $15 \mathrm{~min}$. After the filter was removed, the solvent was evaporated to dryness, and subsequently the residue was dissolved in $1 \mathrm{~mL}$ toluene and applied to a silica column (length $120 \mathrm{~mm}$, I.D. $5 \mathrm{~mm}$; filled with $0.8 \mathrm{~g}$ silica (silica gel 60, purest, Merck)). Elution was carried out consecutively with $5 \mathrm{~mL}$ toluene, $15 \mathrm{~mL}$ dichloromethane, and $5 \mathrm{~mL}$ methanol. Each solution was collected, filtered $(0.2-\mu \mathrm{m}$ PTFE, 4-mm syringe filter, Alltech, Norderstedt, Germany), evaporated to dryness under a nitrogen stream, and resolved in $75 \mu \mathrm{L} \mathrm{MeOH}$. DCM and $\mathrm{MeOH}$ fractions were subjected to HPLC separation.

\section{LC-API-MS}

An Agilent micro HPLC system (series 1100, Waldbronn, Germany) was used in connection with a single-quadrupole mass spectrometer (MSD SL, Waldbronn, Germany). The apparatus consisted of a quaternary capillary pump (G1376A), a degasser unit (G1379A), an auto sampler (G1377A), and a column in a thermostat (G1316A) set to $40^{\circ} \mathrm{C}$. The massselective detector (G1956B) was connected by an APCI interface (G1947A) or an APPI interface (G1971A). HPLC, ionization, and the mass spectrometric detector were controlled and data were analyzed using ChemStation software (Rev. B.01.01, Agilent, Waldbronn, Germany).

The chromatographic separation was performed with a Nucleosil 120-7C6H5 column $(250 \mathrm{~mm} \times 4 \mathrm{~mm}$ I.D., $7 \mu \mathrm{m}$ spherical, not endcapped; CS, Langerwehe, Germany) with $\mathrm{MeOH}-\mathrm{H}_{2} \mathrm{O}$ as the mobile phase at a flow rate of $500 \mu \mathrm{L}$ $\min ^{-1}$ and an injection volume of $5 \mu \mathrm{L}$. The mobile phase was $\mathrm{MeOH}-\mathrm{H}_{2} \mathrm{O}, 80: 20(v / v)$ at the beginning of a 
chromatographic run and increased within 2 min to $100 \%$ $\mathrm{MeOH}$ to achieve rapid elution of the oxidation products. This was held for $54 \mathrm{~min}$ to elute also the strongly hydrophobic compounds. Finally, the mobile phase composition was reset to initial conditions within $4 \mathrm{~min}$.

Note that during analysis of the samples the pressure in the HPLC system increased, obviously caused by the high contamination potential of the samples, even after filtration. One should use pre-columns if a larger number of samples are to be analysed.

The mass spectrometric interface settings were analogous to the APCI and APPI conditions published previously [25]: $350{ }^{\circ} \mathrm{C}$ drying gas temperature, $360 \mathrm{~L} \mathrm{~h}^{-1}$ drying gas flow, $4.13 \times 10^{5} \mathrm{~Pa}$ nebulizer gas pressure (gauge pressure), and $225^{\circ} \mathrm{C}\left(\right.$ APCI) or $275^{\circ} \mathrm{C}$ (APPI) vaporizer temperature.

Mass spectrometric detection was performed in positiveion mode. For detection a capillary potential of $2500 \mathrm{~V}$ (APCI) or $1500 \mathrm{~V}$ (APPI) was used, a "fragmentor" potential of $100 \mathrm{~V}$ (APCI) or $200 \mathrm{~V}$ (APPI), and for APCI a corona current of $7 \mu \mathrm{A}$. The scan range was set to 250 $400 \mathrm{~m} / \mathrm{z}$ (for the coronene samples) and $350-650 \mathrm{~m} / \mathrm{z}$ (for the HBC samples).

\section{Results and discussion}

\section{Oxidation of giant PAHs}

Table 1 summarizes the reaction conditions achieved in the experimental setup and applied to coronene and $\mathrm{HBC}$ samples for intensive oxidation with oxygen and $\mathrm{NO}_{2}$. The three samples of $\mathrm{HBC}$ at lower temperature $(\mathrm{H} 2-\mathrm{H} 4)$ were performed consecutively due to the low reactivity of $\mathrm{HBC}$, meaning the extracted filter of the previous experiment with probably pre-oxidised (but still insoluble) HBC was again exposed to the reaction gases.

The gas mixture consisted of moistened nitrogen together with different ratios of $\mathrm{NO}_{2}$ and $\mathrm{O}_{2}$. For coronene sample $\mathrm{C} 1, \mathrm{NO}_{2}$ was not the only reactive species, but also

Table 1 Reaction conditions for the moistened coronene (C1-C3) and the HBC (H1-H4) samples

\begin{tabular}{|c|c|c|}
\hline No. & \multicolumn{2}{|c|}{ Reaction conditions } \\
\hline $\mathrm{C} 1$ & Coronene & $500 \mathrm{ppm} \mathrm{NO}_{2}, 150{ }^{\circ} \mathrm{C}, 2 \mathrm{~h}$ \\
\hline $\mathrm{C} 2$ & & $500 \mathrm{ppm} \mathrm{NO}_{2}, 150{ }^{\circ} \mathrm{C}, 2 \mathrm{~h}, 50 \% \mathrm{O}_{2}$ \\
\hline $\mathrm{C} 3$ & & $500 \mathrm{ppm} \mathrm{NO}_{2}, 22^{\circ} \mathrm{C}, 2 \mathrm{~h}, 50 \% \mathrm{O}_{2}$ \\
\hline H1 & $\mathrm{HBC}$ & $250 \mathrm{ppm} \mathrm{NO}_{2}, 350{ }^{\circ} \mathrm{C}, 1 \mathrm{~h}$ \\
\hline $\mathrm{H} 2$ & & $500 \mathrm{ppm} \mathrm{NO} \mathrm{NO}_{2}, 150{ }^{\circ} \mathrm{C}, 1 \mathrm{~h}$ \\
\hline H3 & & $500 \mathrm{ppm} \mathrm{NO}_{2}, 150{ }^{\circ} \mathrm{C}, 1 \mathrm{~h}, 50 \% \mathrm{O}_{2}$ \\
\hline $\mathrm{H} 4$ & & $250 \mathrm{ppm} \mathrm{NO}_{2}, 22{ }^{\circ} \mathrm{C}, 1 \mathrm{~h}, 75 \% \mathrm{O}_{2}$ \\
\hline
\end{tabular}

$\mathrm{HNO}_{2}$ and $\mathrm{HNO}_{3}$ which are formed in the wet environment due to disproportionation of $\mathrm{NO}_{2}$. The temperature for sample $\mathrm{C} 2$ was the same as for $\mathrm{C} 1\left(150{ }^{\circ} \mathrm{C}\right)$, however $50 \%$ $\mathrm{O}_{2}$ was present. This leads to a higher content of $\mathrm{HNO}_{3}$ in the reaction gas due to oxidation of $\mathrm{HNO}_{2}$. The oxidation effect on the PAHs will be stronger since $\mathrm{HNO}_{3}$ has greater oxidation strength than $\mathrm{HNO}_{2}$ and a large amount of $\mathrm{O}_{2}$ is present. The reaction environment of sample $\mathrm{C} 3$ may be less harsh compared with $\mathrm{C} 2$ due to the lower reaction temperature $\left(22^{\circ} \mathrm{C}\right)$.

The reaction conditions for $\mathrm{HBC}$ varied between 22 and $350{ }^{\circ} \mathrm{C}, 250$ and $500 \mathrm{ppm} \mathrm{NO}_{2}$, and 0 and $75 \% \mathrm{O}_{2}$ to achieve strongly different oxidation states.

Exposure of the large PAHs-loaded filter to reaction gas should, in principle, lead to physisorption and chemisorption of reactive species $\left(\mathrm{NO}_{2}, \mathrm{HNO}_{3}\right)$, and subsequent degradation of the PAHs by formation of different oxygencontaining groups (e.g. carbocyclic acids, lactones, $\mathrm{R}-\mathrm{NO}_{2}$ and R-ONO functionalities). During reaction these intermediate products will decompose, either thermally or chemically by oxidising species, releasing $\mathrm{CO}_{2}, \mathrm{NO}$, or $\mathrm{CO}$. At elevated temperature thermally induced desorption of oxidised fragments will also occur.

Increasing the reaction temperature therefore has two effects. First, the oxidation will be much faster, which means that a larger fraction of the PAH is converted into an oxidised form. Second, however, this can also lead to a higher amount of volatile species which may not remain on the filter for further analysis. However, due to the large aromatic backbone and the applied cooling by liquid nitrogen, the amount of oxidised species on the filter should remain high.

Analysis of giant PAH oxidation products

\section{Pre-separation by solid-phase-extraction}

As proven earlier for benzo $[a]$ pyrene samples, the toluene extract contains unreacted PAH $[27,28]$. Due to the main presence of polar oxidation products in $\mathrm{DCM}$ and $\mathrm{MeOH}$ fractions, only these were subjected to HPLC analysis. The great majority of compounds formed during oxidation of coronene were found in the DCM fraction, thus only the DCM results will be discussed. The extraction of oxidized $\mathrm{HBC}$ led to oxidation compounds in both the DCM and the HBC solution.

\section{Fast LC-API-MS}

The applied column and mobile phase was not adopted to obtain an appropriate analytical separation of the oxidation products by reversed-phase LC. In fact, it was used to have slight retention on the chromatographic column for the 
compounds of interest. Thus, they can be separated from ionic compounds and from non-oxidized hydrophobic PAH. The former compounds elute from the column without being retarded and the latter are retained very strongly on the reversed-phase column. Both classes of compound may show high signal-suppressing effects in mass spectrometric detection due to neutralization, clustering, and/or adduct formation effects similar to electrospray ionization [32-34]. Thus it is proposed to separate them by LC at least some seconds from the molecules of interest.

The high methanol content in the first time section caused fast, but broad elution of compounds, because efficient retention of various compounds was absent. The two chromatographic peaks elute with a retention width of a few minutes, as can be seen in the total ion chromatogram (TIC) in Fig. 3a. The extraction of single mass traces

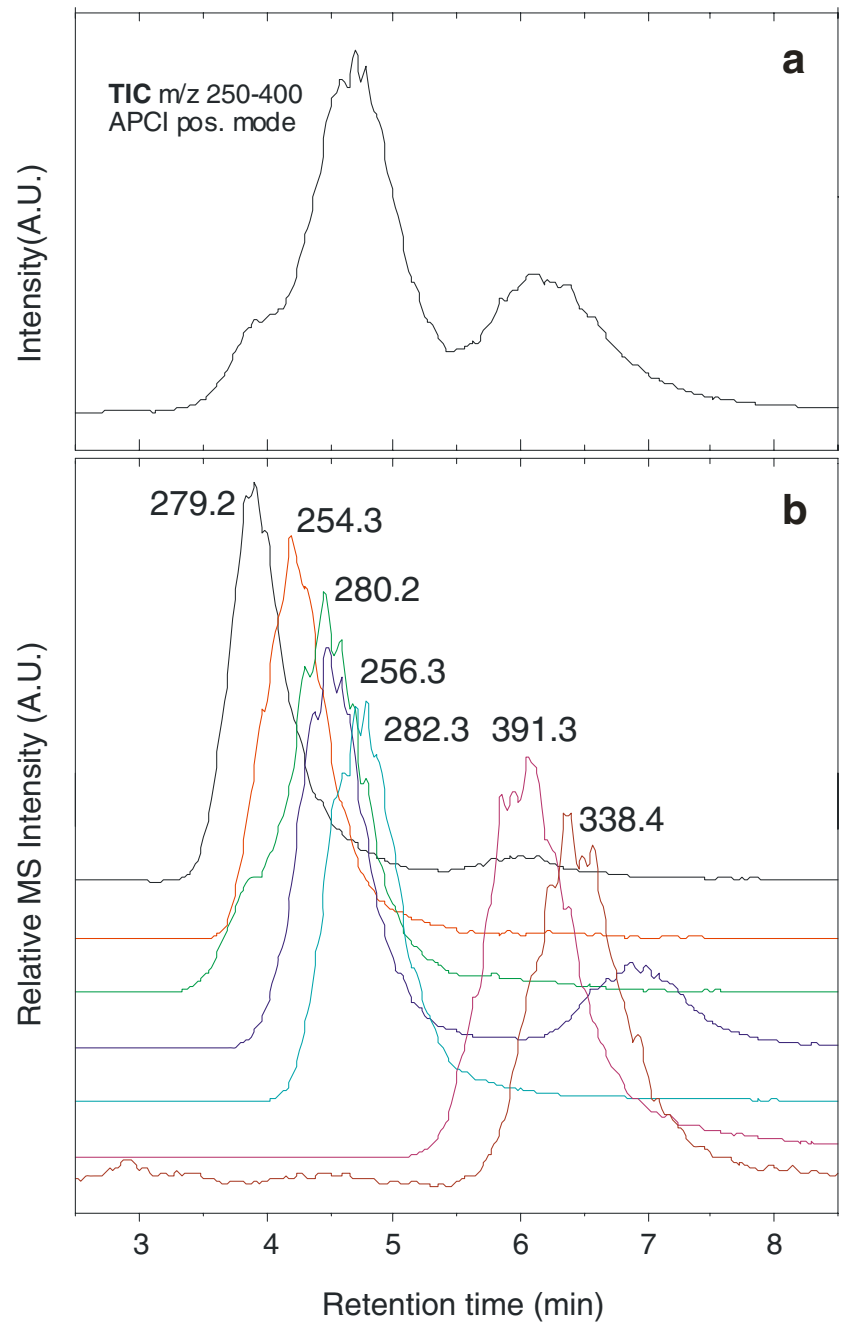

Fig. 3 Chromatograms obtained from the DCM fraction of the coronene sample C2. (a) total-ion chromatogram (TIC, $\mathrm{m} / \mathrm{z}^{2} 250$ 400); (b) normalized extracted-ion chromatograms (EIC) for prominent masses of sample C2 (DCM fraction) displayed as extracted ion chromatograms (EICs) discloses a rather more detailed view of the behaviour of the oxidation products (e.g. Fig. 3b). Please note that the adopted separation should be applied for comparison with our earlier studies $[27,28]$, but should not illustrate an optimized separation method. Furthermore, the long time at high methanol content may ensure major elution of nonreacted PAHs.

Several compounds shown in the EICs of Fig. $3 b$ have been ionized by one of the two commercially available ionization techniques for "semipolar" molecules, APCI and APPI. Generally, oxidized PAHs are rarely ionised in solution and have therefore to become charged in the transfer region of the mass spectrometer. At the beginning of the study a test was performed to determine whether the source properties (section $L C$-API-MS) for oxidized species of the large PAHs were similar to those for partially oxidized PAHs up to five condensed aromatic rings, as

\section{a}
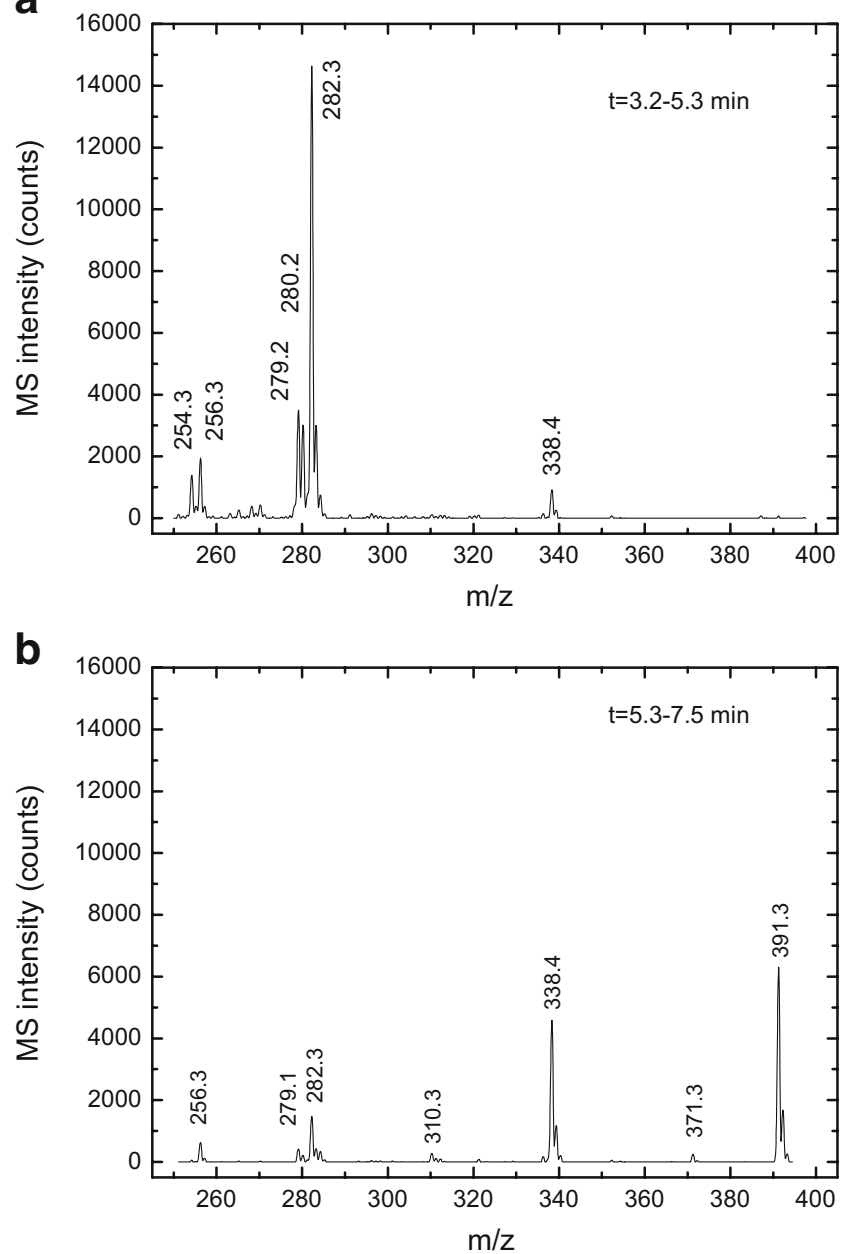

Fig. 4 Mass spectra of coronene sample C2 (DCM fraction) for two different TIC integration regions (Fig. 3a): (a) $t=3.2-5.3 \mathrm{~min}$, (b) $t=$ $5.3-7.5 \mathrm{~min}$ 
Table 2 EIC retention time and peak integral of prominent masses of coronene samples (DCM fraction)

\begin{tabular}{|c|c|c|c|c|c|c|c|c|c|}
\hline \multirow[b]{2}{*}{$\mathrm{m} / \mathrm{z}$} & \multicolumn{3}{|l|}{$\mathrm{C} 1$} & \multicolumn{3}{|l|}{$\mathrm{C} 2$} & \multicolumn{3}{|l|}{$\mathrm{C} 3$} \\
\hline & $\mathrm{RT}$ [min] & Int. [A.U.] & Int. [\%] & $\mathrm{RT}$ [min] & Int. [A.U.] & Int. [\%] & $\mathrm{RT}$ [min] & Int. [A.U.] & Int. [\%] \\
\hline \multirow[t]{2}{*}{256.3} & 4.7 & $3.4+06$ & 1.1 & 4.5 & $3.3 \mathrm{E}+06$ & 12.2 & 4.1 & $5.2 \mathrm{E}+06$ & 0.9 \\
\hline & 7.0 & $8.6 \mathrm{E}+05$ & 0.3 & 6.9 & $9.2 \mathrm{E}+05$ & 3.4 & 6.6 & $7.2 \mathrm{E}+05$ & 0.1 \\
\hline \multirow[t]{2}{*}{279.2} & 4.0 & $3.9 \mathrm{E}+06$ & 1.2 & 3.9 & $5.7 \mathrm{E}+06$ & 21.1 & 3.8 & $6.6 \mathrm{E}+06$ & 1.2 \\
\hline & & & & 6.0 & $4.1 \mathrm{E}+05$ & 1.5 & 5.0 & $7.8 \mathrm{E}+05$ & 0.1 \\
\hline 280.2 & 4.5 & $2.7 \mathrm{E}+06$ & 0.8 & 4.5 & $4.3 \mathrm{E}+06$ & 15.9 & 4.1 & $5.2 \mathrm{E}+06$ & 0.9 \\
\hline \multirow[t]{2}{*}{282.3} & 5.0 & $1.3 \mathrm{E}+07$ & 4.1 & 4.8 & $2.7 \mathrm{E}+07$ & 100.0 & 4.2 & $2.5 \mathrm{E}+07$ & 4.5 \\
\hline & 6.6 & $1.5 \mathrm{E}+06$ & 0.5 & & & & & & \\
\hline 310.3 & & & & & & & 4.7 & $2.6 \mathrm{E}+07$ & 4.7 \\
\hline \multirow[t]{2}{*}{336.3} & 4.7 & $7.8 \mathrm{E}+06$ & 2.4 & & & & 4.0 & $1.6 \mathrm{E}+07$ & 2.9 \\
\hline & 6.1 & $9.8 \mathrm{E}+06$ & 3.1 & & & & 4.7 & $1.3 \mathrm{E}+07$ & 2.4 \\
\hline 338.4 & 6.6 & $6.2 \mathrm{E}+08$ & 100.0 & 6.4 & $6.6 \mathrm{E}+06$ & 24.4 & 5.2 & $5.5 \mathrm{E}+08$ & 100.0 \\
\hline 352.3 & 5.3 & $6.5 \mathrm{E}+06$ & 2.0 & & & & 4.5 & $1.8 \mathrm{E}+07$ & 3.3 \\
\hline 391.3 & & & & 6.1 & $1.0 \mathrm{E}+07$ & 37.0 & 5.2 & $9.0 \mathrm{E}+06$ & 1.6 \\
\hline
\end{tabular}

published previously [25]. Comparison for positive-ion mode showed similar ionization behaviour and signal efficiency for both interfaces (data not presented). Please note in the forthcoming results we describe the mass spectrometric detection solely with APCI in positive-ion mode. However, one has to keep in mind, that APPI gave exactly the same results, i.e. solely results with minimum two independent experiments were interpreted in the forthcoming paragraphs.

\section{Reaction of coronene}

Again, Fig. 3 presents the (a) TIC and (b) EICs of the DCM fraction obtained from sample $\mathrm{C} 2$. The EICs originated from the masses contributing to the TIC; typical mass spectra of this sample are shown in Fig. 4. It can be clearly seen that different elution maxima (Fig. 3b) and different peak shapes of the EICs result from different molecules. The extracted ion chromatograms for the six most prominent masses in Table $2(\mathrm{~m} / \mathrm{z} 256,279,280,282,338$, and 391 ) are depicted in Fig. $3 b$ by increasing retention time. Most dominating masses indicate that every $\mathrm{m} / \mathrm{z}$ value belongs to a distinct group of oxidation products. For instance, the molecule with the highest intensity in $\mathrm{C} 2$ has $m / z 282$; it is shown in Fig. 5a with its proposed chemical structure. Most of the compounds in Table 2 contain an odd number of nitrogen atoms, due to the even molecular mass of $[\mathrm{M}+\mathrm{H}]^{+}$ions, e.g. $m / z$ 282, 338, and 352 (Figs. 5a,b, and $\mathrm{c}$, respectively). Protonated molecules without nitrogen or an even number of nitrogen in contrast have an odd $\mathrm{m} / \mathrm{z}$ in the mass spectrum (e.g. the compound in Fig. 5d).

Some $m / z$ values exhibit two separated peaks, e.g. $\mathrm{m} / \mathrm{z}$ 256. This can be probably attributed to isomers with different retention times due to intra-molecular hydrogen bonding of contained functional groups [25]. Furthermore, the same procedure of extracting the most intense mass signals was repeated for the two other coronene DCM solutions ( $\mathrm{C} 1$ and $\mathrm{C} 3$ ). Table 2 summarizes the six to nine most prominent $\mathrm{m} / \mathrm{z}$ values with retention times and integrated peak area (EIC) of all three DCM solutions. The different oxidation conditions are reflected in the varying intensities of the oxidation products. For samples $\mathrm{C} 1$ and $\mathrm{C} 3, \mathrm{~m} / \mathrm{z} 338$ (Fig. 5b) is the dominating mass, the relative intensity of the other $\mathrm{m} / \mathrm{z}$ values being smaller than $10 \%$. When oxygen is added (C2 and C3) and at elevated oxidation temperature (C2), the intensity of $\mathrm{m} / \mathrm{z} 391$ increases, whereas at room temperature (C3) the intensity of $\mathrm{m} / \mathrm{z} 391$ is low. Additionally, the $\mathrm{m} / \mathrm{z}$ value 310 appears, being a)

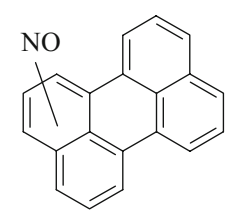

b)<smiles>NC1(O)C2=CC=C3C=Cc4ccc5c(c43)C(=C1C=C2)C(=O)C=C5</smiles>

$\mathrm{C}_{20} \mathrm{H}_{11} \mathrm{~N}_{1} \mathrm{O}_{1}$, MW 281

c)

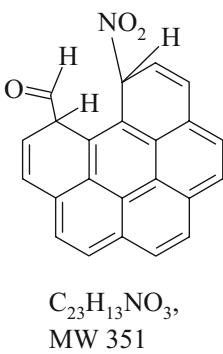

$\mathrm{C}_{22} \mathrm{H}_{11} \mathrm{~N}_{1} \mathrm{O}_{3}$, MW 337

d)

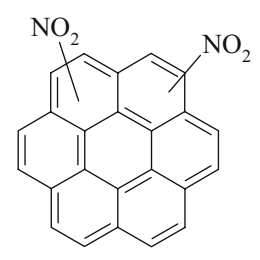

$\mathrm{C}_{24} \mathrm{H}_{10} \mathrm{~N}_{2} \mathrm{O}_{4}$, MW 390
Fig. 5 Proposed structures of four coronene nitration/oxidation products that were tentatively identified by fingerprint LC-API-MS; in several cases, other isomers are equally probable 

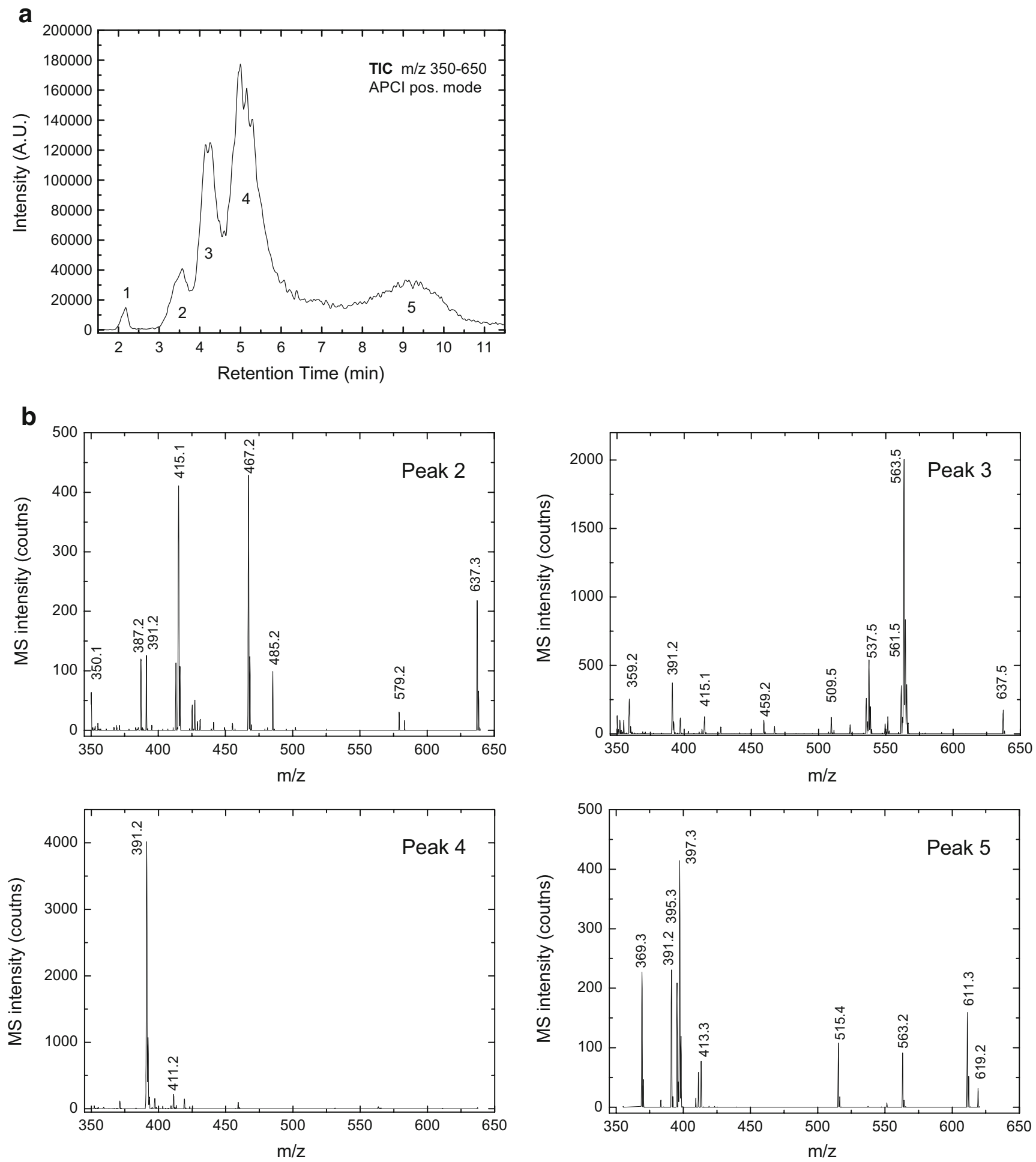

Fig. 6 (a) TIC of DCM fraction of sample H2. (b) For peaks 2-5 the MS spectra are given

the second most intense peak for the room-temperature oxidized sample $\mathrm{C} 3$. Furthermore, another consequence of the $\mathrm{O}_{2}$ addition at high temperature $(\mathrm{C} 2)$ is the small absolute amount of detected products in the sample. This is obviously due to the harsher oxidation conditions, leading to the formation of smaller, more volatile organic compounds or even species like $\mathrm{CO}$ or $\mathrm{CO}_{2}$, which are released from the filter. On the other hand the room-temperature sample $\mathrm{C} 3$ 
contains the highest variety of oxidized compounds in the mass spectrometric range 200-400 Da and the highest compound intensities. This could be explained by the lower oxidation efficiency at room temperature and, therefore, more non-volatile compounds. The masses 256, 279, 280, and 282 are present in all samples with similar intensity indicating that the compounds can be formed independently from oxygen availability and elevated temperature.
Reaction of $\mathrm{HBC}$

The pre-separation showed different effects on the HBC samples compared with the coronene samples. Oxidation products can be found in both the DCM and the $\mathrm{MeOH}$ fractions.

Figure 6 a shows a typical TIC for $\mathrm{H} 2$, clearly reflecting the higher hydrophobicity of some products, but also showing signals that are comparable with coronene products. Again

Table 3 EIC retention time and peak integral for the most prominent $m / z$ values (max. 6) of DCM and MeOH fractions of HBC samples

\begin{tabular}{|c|c|c|c|c|c|c|c|c|c|c|c|c|}
\hline $\mathrm{m} / \mathrm{z}$ & $\begin{array}{l}\text { RT } \\
{[\mathrm{min}]}\end{array}$ & $\begin{array}{l}\text { Int. } \\
\text { [A.U.] }\end{array}$ & Int. [\%] & $\begin{array}{l}\text { RT } \\
{[\mathrm{min}]}\end{array}$ & $\begin{array}{l}\text { Int. } \\
\text { [A.U.] }\end{array}$ & $\begin{array}{l}\text { Int. } \\
{[\%]}\end{array}$ & $\begin{array}{l}\text { RT } \\
{[\mathrm{min}]}\end{array}$ & $\begin{array}{l}\text { Int. } \\
\text { [A.U.] }\end{array}$ & $\begin{array}{l}\text { Int. } \\
{[\%]}\end{array}$ & $\begin{array}{l}\text { RT } \\
{[\mathrm{min}]}\end{array}$ & $\begin{array}{l}\text { Int. } \\
\text { [A.U.] }\end{array}$ & $\begin{array}{l}\text { Int. } \\
{[\%]}\end{array}$ \\
\hline & \multicolumn{3}{|c|}{ H1_DCM } & \multicolumn{3}{|c|}{$\mathrm{H} 1 \_\mathrm{MeOH}$} & \multicolumn{3}{|c|}{ H2_DCM } & \multicolumn{2}{|c|}{ H2_MeOH } & \\
\hline 352.3 & 4.5 & $1.3 \mathrm{E}+07$ & 100.0 & & & & & & & & & \\
\hline 354.3 & 4.7 & $7.1 \mathrm{E}+06$ & 53.8 & & & & & & & & & \\
\hline 359.2 & & & & 4.7 & $1.4 \mathrm{E}+05$ & 7.9 & & & & 4.6 & 3.2E07 & 100.0 \\
\hline \multirow[t]{2}{*}{366.3} & 4.1 & $1.5 \mathrm{E}+06$ & 11.0 & & & & & & & & & \\
\hline & 5.8 & $9.0 \mathrm{E}+06$ & 67.6 & & & & & & & & & \\
\hline 369.3 & & & & & & & 8.2 & $4.9 \mathrm{E}+05$ & 8.9 & & & \\
\hline 387.1 & & & & 3.5 & $1.3 \mathrm{E}+05$ & 7.2 & & & & & & \\
\hline 391.2 & 5.1 & $7.7 \mathrm{E}+06$ & 57.9 & 5.2 & $1.8 \mathrm{E}+06$ & 100.0 & 5.0 & $5.5 \mathrm{E}+06$ & 100.0 & & & \\
\hline \multirow[t]{2}{*}{397.3} & & & & & & & 6.2 & $2.4 \mathrm{E}+05$ & 4.4 & & & \\
\hline & & & & & & & 9.1 & $1.2 \mathrm{E}+06$ & 21.3 & & & \\
\hline 415.1 & & & & & & & & & & 3.9 & $6.6 \mathrm{E}+06$ & 20.6 \\
\hline 515.3 & 9.5 & $5.4 \mathrm{E}+06$ & 40.9 & 10.5 & $3.5 \mathrm{E}+05$ & 19.7 & & & & & & \\
\hline 537.5 & & & & 8.1 & $6.3 \mathrm{E}+04$ & 3.5 & & & & 4.3 & $5.5 \mathrm{E}+06$ & 17.1 \\
\hline \multicolumn{13}{|l|}{551.5} \\
\hline 561.4 & & & & & & & & & & 4.4 & $5.7 \mathrm{E}+06$ & 17.8 \\
\hline \multirow[t]{2}{*}{563.5} & & & & & & & 4.3 & $1.1 \mathrm{E}+06$ & 20.5 & 4.5 & $2.4 \mathrm{E}+07$ & 74.0 \\
\hline & & & & & & & 9.3 & $1.2 \mathrm{E}+05$ & 2.1 & & & \\
\hline 611.3 & & & & & & & 7.1 & $5.2 \mathrm{E}+05$ & 9.4 & & & \\
\hline \multirow[t]{2}{*}{637.3} & & & & & & & & & & 4.7 & $1.9 \mathrm{E}+07$ & 60.3 \\
\hline & \multicolumn{3}{|c|}{ H3_DCM } & \multicolumn{3}{|c|}{ H3_MeOH } & \multicolumn{3}{|c|}{ H4_DCM } & \multicolumn{3}{|c|}{ H4_MeOH } \\
\hline 352.3 & 4.4 & $9.0 \mathrm{E}+06$ & 100.0 & & & & & & & & & \\
\hline 354.3 & 5.0 & $4.7 \mathrm{E}+06$ & 51.7 & & & & & & & & & \\
\hline 359.2 & & & & & & & & & & 4.4 & $8.9 \mathrm{E}+06$ & 47.2 \\
\hline \multirow[t]{2}{*}{366.3} & 3.8 & $1.0 \mathrm{E}+06$ & 11.1 & & & & & & & & & \\
\hline & 5.8 & $6.5 \mathrm{E}+06$ & 72.0 & & & & & & & & & \\
\hline \multirow[t]{2}{*}{369.3} & 3.3 & $3.4 \mathrm{E}+06$ & 37.4 & & & & 8.3 & $5.7 \mathrm{E}+05$ & 5.9 & & & \\
\hline & 5.1 & $6.5 \mathrm{E}+05$ & 7.2 & & & & & & & & & \\
\hline \multicolumn{13}{|l|}{387.1} \\
\hline 391.2 & & & & 4.4 & $2.8 \mathrm{E} 0+06$ & 100.0 & 5.1 & $9.6 \mathrm{E}+06$ & 100.0 & 5.0 & $4.6 \mathrm{E}+06$ & 24.5 \\
\hline \multicolumn{13}{|l|}{397.3} \\
\hline 415.1 & & & & & & & & & & 3.5 & $2.2 \mathrm{E}+06$ & 11.9 \\
\hline 515.3 & & & & 8.7 & $1.5 \mathrm{E}+06$ & 52.5 & & & & & & \\
\hline \multicolumn{13}{|l|}{537.5} \\
\hline \multirow[t]{2}{*}{551.5} & 3.3 & $1.5 \mathrm{E}+06$ & 16.9 & & & & & & & & & \\
\hline & 3.5 & $6.8 \mathrm{E}+05$ & 7.5 & & & & & & & & & \\
\hline \multicolumn{13}{|l|}{561.4} \\
\hline 563.5 & & & & & & & & & & 4.2 & $5.4 \mathrm{E}+06$ & 29.0 \\
\hline 611.3 & & & & & & & 7.1 & $6.1 \mathrm{E}+05$ & 6.3 & & & \\
\hline 637.3 & & & & & & & & & & 4.4 & $1.9 \mathrm{E}+07$ & 100.0 \\
\hline
\end{tabular}


a

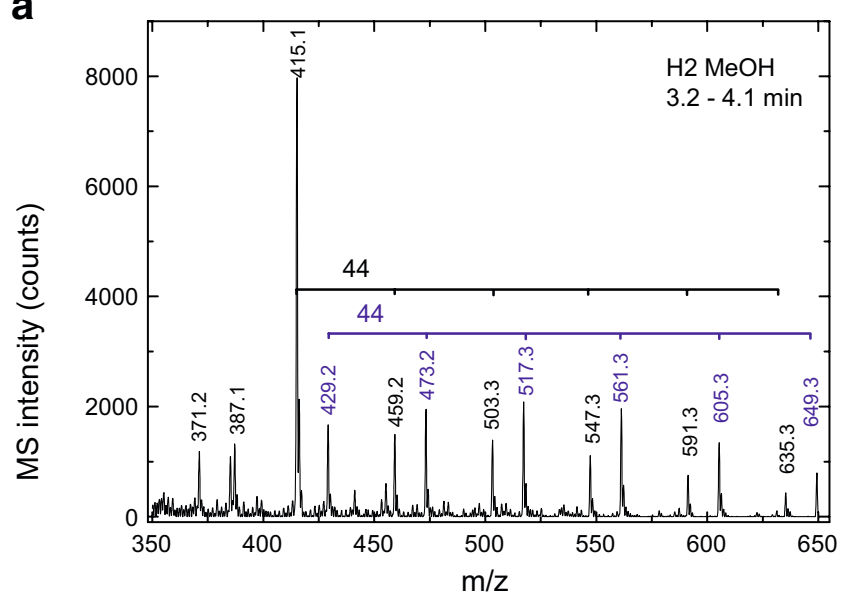

b

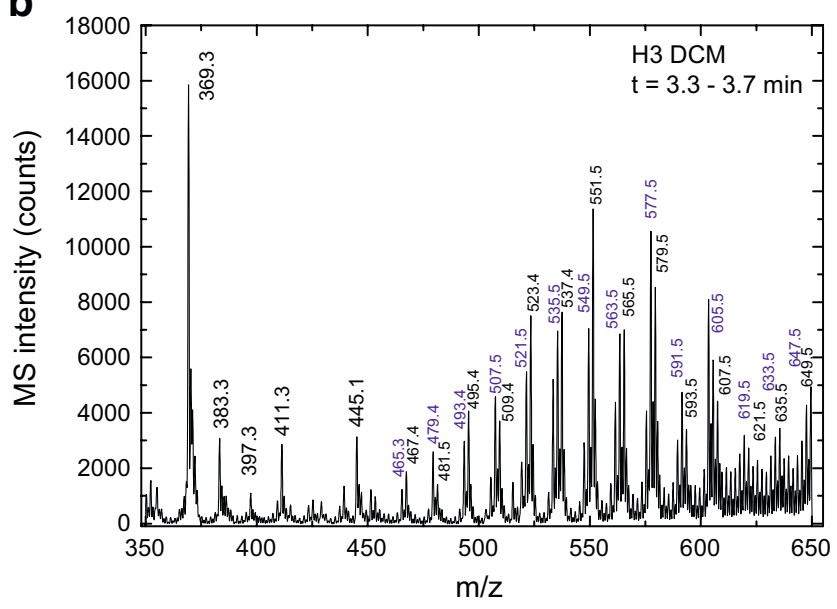

Fig. 7 (a) Mass spectrum $(t=3.2-4.1 \mathrm{~min})$ of sample $\mathrm{H} 2, \mathrm{MeOH}$ fraction. Two series of $\mathrm{m} / z$ values, separated by $\mathrm{m} / \mathrm{z} 44$ are visible. (b) MS spectrum $(t=3.3-3.7 \mathrm{~min})$ of sample H3, DCM fraction. This shows two series of peaks, separated by $\mathrm{m} / \mathrm{z} 14$

there are several compounds behind each signal as can be seen in the four mass spectra of Fig. 6b. The $m / z$ values obtained are also independent of each other, as checked for the six most prominent peaks in the EICs (data not shown).

Table 3 presents the most intense $\mathrm{m} / \mathrm{z}$ values from the TIC of several DCM and $\mathrm{MeOH}$ solutions by increasing ion masses. Compounds with $m / z>522$ (e.g. 611, 563, 637) appeared, and may be oxygen-containing HBC fragments, or larger molecules, formed during the oxidation process. The masses and amounts of oxidized compounds is different for all HBC samples. However, $\mathrm{m} / \mathrm{z} 352$ and $\mathrm{m} / \mathrm{z}$ 391 could also be found in most samples. Generally, for this purpose also, very high temperatures led to compounds with high polarity and lower molecular masses as in sample H1. Elevated temperatures led to a mixture of several compounds (H2). Finally, the addition of oxygen (H3 and $\mathrm{H} 4)$ led to a more complicated picture, however the degradation is less effective than at $350{ }^{\circ} \mathrm{C}(\mathrm{H} 1)$.
Last, but not least, some of the derived mass spectra showed very interesting patterns which should be mentioned. The MS signal behind the first chromatographic signal of the $\mathrm{MeOH}$ fraction of sample $\mathrm{H} 2$ (Fig. 7a) offers two sets of masses which are separated by $\mathrm{m} / \mathrm{z} 44$. This could be due to a set of molecules which differ only in their number of carboxyl groups.

In the MS signal of the first chromatographic signal of the DCM fraction of sample $\mathrm{H} 3, \mathrm{~m} / \mathrm{z} 551$ and 577 are surrounded by two series of peaks, separated by $\mathrm{m} / \mathrm{z} 14$, which may be due to $\mathrm{CH}_{2}$. This could be explained by a class of substances which only differ in the length of one or more alkane groups. The pattern was only visible in sample $\mathrm{H} 3$, where $50 \% \mathrm{O}_{2}$ was added during the reaction. The pattern may be a representative of different stages of the oxidation process of the parent molecule HBC. This highlights the excellent application of mass spectrometry although very complex mixtures have to be analysed. Further research should be performed to obtain an overall picture of oxidation mechanism.

\section{Conclusion}

In this publication we presented an easy method for oxidation of large PAHs at elevated temperatures. The oxidation conditions (temperature, exposure time, and gas composition and concentrations) could easily be varied and the cooling of the PAH loaded filter with liquid nitrogen quickly stops the reaction.

Rapid analysis of the oxidation products with SPE and the LC-API-MS compound fingerprint subsequently revealed that in most of the samples a few compounds with specific $\mathrm{m} / \mathrm{z}$ values are present as a stable sink. Whereas coronene oxidation products mainly elute in this study with dichloromethane from the SPE columns, oxidized HBC compounds elute in both the dichloromethane and the methanol fractions. However, a collection foam must be added after the filter to enable analysis of volatile compounds in future experiments.

Dominating compounds of $\mathrm{m} / \mathrm{z} 282$ and $\mathrm{m} / \mathrm{z} 256$ resemble stable oxidation products originating from benzo [a]pyrene (e.g. $\mathrm{m} / z$ 283, and $\mathrm{m} / \mathrm{z} 257$ ) in previous research. $\mathrm{m} / \mathrm{z} 391$ was a major product of every HBC-sample whereas $\mathrm{m} / \mathrm{z} 338$ is the predominant reaction product found in two of the coronene samples.

For identification of these compounds further MS-MS experiments are needed, or a time-of-flight (ToF) mass spectrometer. Accurate mass with high resolution ToF leads to an elemental formula and tandem mass spectrometry to structure identification by compound fragmentation.

The fact that only a few molecules (or isomers) could be found in most of the samples shows that using a well 
defined soot model compound like HBC is promising for further investigations of the oxidation process.

The precise pathway of degradation of large PAH by oxidation and nitration may be clarified by LC-APCI-MS. However, further experiments are necessary with defined conditions, smaller steps in changes of conditions, and mass spectrometers of high accuracy and sensitivity.

Acknowledgement The authors gratefully acknowledge Professor Müllen, Max-Planck Institute for Polymer Research, Mainz, Germany, for providing the HBC. Heun Lee is acknowledged for critical proof reading.

Agilent Technologies is acknowledged for the chromatographic column and loan of a micro LC 1100 series connected to a single-stage quadrupole mass spectrometer (LC-MSD SL) via APPI and APCI.

Open Access This article is distributed under the terms of the Creative Commons Attribution Noncommercial License which permits any noncommercial use, distribution, and reproduction in any medium, provided the original author(s) and source are credited.

\section{References}

1. Sydbom A, Blomberg A, Parnia S, Stenfors N, Sandstrom T, Dahlen S (2001) Eur Respir J 17:733-746

2. Pöschl U, Letzel T, Schauer C, Niessner R (2001) J Phys Chem A 105:4029-4041

3. Pöschl U (2005) Angew Chem Int Ed 44:7520-7540

4. Messerer A, Rothe D, Pöschl U, Niessner R (2004) Top Catal 31:247-250

5. Messerer A, Niessner R, Pöschl U (2003) J Aerosol Sci 34:10091021

6. Messerer A, Schmid H-J, Knab C, Pöschl U, Niessner R (2004) Chem Eng Technol 76:1092-1096

7. Rothe D, Zuther FI, Jacob E, Messerer A, Pöschl U, Niessner R et al (2004) SAE technical paper 2004-01-3046
8. Su DS, Jentoft RE, Müller J-O'Rothe D, Jacob E, Simpson CD, Tomovic Z, Müllen K, Messerer A, Pöschl U, Niessner R, Schlögl R (2004) Catal Today 90:127-132

9. Smith DM, Chughtai AR (1995) Colloids Surf A 105:47-77

10. Mawhinney DB, Yates JT (2001) Carbon 39:1167-1173

11. Muckenhuber H, Grothe H (2004) Top Catal 30/31:287-291

12. Muckenhuber H, Grothe H (2006) Carbon 44:546-559

13. Kirchner U, Scheer V, Vogt R (2000) J Phys Chem A 104:89088915

14. Stanmore BR, Brilhac JF, Gilot P (2001) Carbon 39:2247-2268

15. Messerer A, Niessner R, Pöschl U (2006) Carbon 44:307-324

16. Müller JO, Su DS, Jentoft RE, Wild U, Schlögl R (2006) Environ Sci Technol 40:1231-1236

17. Müller JO, Su DS, Jentoft RE, Kröhnert J, Jentoft FC, Schlögl R (2005) Catal Today 102:259-265

18. Sadezky A, Muckenhuber H, Grothe H, Niessner R, Pöschl U (2005) Carbon 43:1731-1742

19. Homann KH (1998) Angew Chem Int Ed 37:2435-2451

20. Oberlin A (1989) In: Thrower PA (ed) Chemistry and physics of carbon. Dekker, New York

21. Sze S-K, Siddique N, Sloan J, Escribano R (2001) Atmos Environ 35:561-568

22. Ferrari AC, Robertson J (2000) J Phys Rev B 61:14095-14107

23. Reemtsma R (2003) J Chromatogr A 1000:477-501

24. Galceran MT, Moyano E (1996) J Chromatogr A 731:75-84

25. Grosse S, Letzel T (2007) J Chromatogr A 1139:75-83

26. Marvin CH, Smith RW, Bryant DW, Mc Carry BE (1999) J Chromatogr A 863:13-24

27. Letzel T, Pöschl U, Wissiack R, Rosenberg E, Grasserbauer M, Niessner R (2001) Anal Chem 73:1634-1645

28. Letzel T, Rosenberg E, Wissiack R, Grasserbauer M, Niessner R (1999) J Chromatogr A 855:501-514

29. Schauer C, Niessner R, Pöschl U (2004) Anal Bioanal Chem 378:725-736

30. Barco G, Maranzana A, Ghigo G, Causa M, Tonachini G (2006) J Chem Phys 125(194706):1-12

31. Adelhelm C, Niessner R, Pöschl U (2004) J Aerosol Sci 35:S173S174

32. Meng CK, Fenn JB (1991) Org Mass Spectrom 26:542-549

33. Ikonomou MG, Blades AT, Kebarle P (1991) Anal Chem 63:1989-1998

34. Kebarle P, Tang L (1993) Anal Chem 65:972A-986A 